\title{
O SIGNIFICADO DA ADMINISTRAÇĀO APLICADA À ENFERMAGEM SEGUNDO A OPINIĀO DE GRADUANDAS
}

\author{
Paulina Kurcgant* \\ Maria Madalena J. Leite** \\ Raquel R. Gaidzinski*** \\ Heloisa H. C. Peres****
}

KURCGANT, P. et al. O significado da administraçào aplicada à enfermagem segundo a opinião de graduandas. Rev. Esc. Enf. USP „ v.28, n.1, p. 15-26, abril, 1994.

Este estudo teve por objetivo conhecer as opiniöes que as alunas têm, quando chegam para cursar a disciplina Administraçào aplicada à Enfermagem. Para tanto, coletou-se as opiniōes de 30 alunas do $8^{\circ}$ semestre do Curso de Graduação da EEUSP. Os resultados mostraram que as alunas consideram a administraçào como uma forma de organizar o trabalho e que a funçāo administrativa da enfermeira conaiste em conciliar a assistência com a burocracia do serviço.

UNITERMOS: Administração em enfermagem.Educação em enfermagem.

\section{INTRODUÇĀO}

No decorrer de nossa vivência profissional, como docentes da disciplina "Administraçāo aplicada à Enfermagem" do Curso de Graduaçāo em Enfermagem e Obstetrícia da Escola de Enfermagem da USP (EEUSP), temos percebido que essa disciplina tem sido, freqüentemente, entendida pelas alunas, docentes de outras disciplinas e enfermeiras do campo como a que possibilita, às alunas, desenvolver atividades administrativas para gerenciar o Serviço de Enfermagem. Entretanto, muitas vezes, essas atividades tem sido compreendidas como burocráticas.

Segundo TREVIZAN" ${ }^{11}$ as enfermeiras, revelam nos seus discursos que a sua função nảo pode ser burocratizada, cabendo-lhes a realização das atividades da assistência direta aos pacientes.

Profeasor Aasociado da Disciplina Administração Aplicada à Enfermagem do Departamento de Orientação Profteaional (ENO) de EEUSP.

- Profeasor Doutor da Disciplina Adminiatraçảo Aplicada à Enfermagem do Departamento ENO da EEUSP.

-.. Auxiliar de Enaino da Disciplina Administraçào Aplicada a Enfermagem do Departamento ENO da EEUSP.

•... Assistente da Disciplina Adminıstraçåo Aplicada à Enfermagem do Departamento ENO da EEUSP. 
NAKAMAE ${ }^{10}$, também se refere ao dilema que a enfermeira vem vivenciando, dividida entre o prestar o cuidado direto ao paciente e exercer funçōes de chefia e supervisão. Considera ainda, que esse dilema tem gerado profundas discussōes sobre a profissāo e a formaçáo de enfermeiras.

Essa situaçăo decorre, fundamentalmente, pelo fato das atividades da enfermagem serem realizadas por uma força trabalho heterogénea quanto à formaçāo profissional, constituida por diferentes categorias de trabalhadores, com diversos niveis de escolaridade, que vão desde o primeiro grau incompleto, até o terceiro grau. Conforme os dados apresentados pelo COFEN-ABEn ${ }^{3}$, no ano de 1985 , no Brasil, o percentual de profissionais era de $8,5 \%$ enfermeiros; $6,6 \%$ técnicos; $21,1 \%$ auxiliares e $63,5 \%$ atendentes de enfermagem.

ALMEIDA $^{1}$ considera que não há como negar a presença maciça do pessoal auxiliar de enfermagem nos serviços de saúde prestando assistência direta aos pacientes. Em vista desse fato, a autora questiona, qual a possibilidade real da enfermeira voltar-se, unicamente, para o cuidado direto à clientela.

TREVIZAN ${ }^{11}$ refere que não se pode continuar insistindo no discurso que reitera o papel da enfermeira, apenas, na assistência direta ao paciente, considerando que a enfermeira deve administrar a assistência prestada aos pacientes e que para tanto a administraçāo é um instrumento para o desenvolvimento da enfermagem.

Acredita-se que a funçāo administrativa da enfermeira é histórica e portanto real. Entretanto vem sendo interpretada, tanto ao nível teórico, quanto ao nível prático, ora como administração da assistência, ora como administração de serviço. Essa ambigüidade é decorrente da falta de definição do que seja administraçāo aplicada à enfermagem.

Corrobora ainda, para essa ambigüidade, o fato da formaçāo da enfermeira ser precipuamente voltada, durante o curso de graduação, para o cuidado direto, contrapondo-se na prática à funçāo administrativa exigida pelas organizaçōes de saúde.

No desenvolvimento da disciplina Administração aplicada à Enfermagem busca-se instrumentalizar a aluna, com princípios, elementos e métodos preconizados pela administração geral, que lhe possibilite, assim, prestar uma assistência de enfermagem eficiente e eficaz.

Diante dessa proposta considera-se importante, realizar um estudo que permita conhecer as impressóes que as graduandas trazem a respeito da referida disciplina ao iniciá-la. Considera-se ainda, que os resultados desse estudo contribuirào para o aprimoramento do ensino na disciplina.

Apenas a título de esclarecimento, o Curso de Graduação da EEUSP está subdividido em dois ciclos: o pré-profissional, compreendendo os dois primeiros semestres e o tronco profissional comum, do $3^{9}$ ao $8^{2}$ semestres. A disciplina Administraçāo aplicada à Enfermagem é ministrada no $8^{0}$ semestre, abrangendo ensino teórico e teórico-prático. 


\section{METODOLOGIA}

O presente estudo baseou-se nas informaçōes obtidas junto a 30 alunas do $8^{2}$ semestre do Curso de Graduação em Enfermagem e Obstetrícia da EEUSP, no ano de 1990.

Para conhecer a opiniāo das alunas sobre administraçāo aplicada à enfermagem, perguntou-se, por escrito, a seguinte questāo: "O que é administraçāo aplicada à enfermagem?".

No primeiro dia de aula da disciplina, explicou-se às alunas os objetivos do presente trabalho, solicitando a colaboraçāo para responderem a questão proposta.

A seguir distribuiu-se as folhas contendo a questão, às 30 alunas presentes, que foram recolhidas imediatamente, após seu preenchimento, nāo se limitando o tempo disponivel para a resposta. Adotou-se esse procedimento para que as alunas não fossem influenciadas pelos conceitos ministrados no decorrer do bloco teórico.

Para organização do conteúdo obtido seguiu-se a orientação de LÜDKE; ANDRE $\hat{E}^{8}$, segundo a qual a a nálise dos dados significa trabalhar todo material obtido durante a pesquisa, organizá-lo, dividindo-o em partes, relacionando essas partes, procurando identificar temas próprios.

Assim, foram realizadas sucessivas leituras de todas as respostas (ANE$\mathrm{XO}$ ), para se identificar os temas emergentes de acordo com o assunto proposto.

Seguindo este percurso foi possivel agrupar os seguintes temas:

- percepção das alunas quanto ao significado da administraçāo;

- percepção das alunas quanto a funçāo administrativa da enfermeira; e

- compreensão das alunas quanto ao foco de atenção da enfermagem.

Finalmente, realizou-se a análise dos temas a luz do referencial teórico.

\section{APRESENTAÇĀO E DISCUSSĀO DOS RESULTADOS}

Conforme descrito na metodologia, a análise das respostas foram organizadas de forma a identificar os temas emergentes relacionados ao estudo proposto.

\section{Percepção das alunas quanto ao significado de administração.}

Nas respostas relativas a esse tema fica evidente que o significado de administraçäo, para as alunas, consiste em organizar os recursos humanos e materiais e o local de serviço. 
Percebe-se ainda, a visāo "controladora", uma vez que se referem a função de administraçáo como a de dirigir, fiscalizar, supervisionar e avaliar. Consideram também, que a finalidade da administração é a de melhorar a qualidade do serviço e da assistência. No entanto, nāo se referem ao desenvolvimento de recursos humanos, demonstrando portanto, um enfoque centrado nas tarefas.

- é organizar, coordenar, orientar e fiscalizar um setor do hospital... istoo engloba o bom funcionamento da unidade.

- organização das tarefas ligadas a área de enfermagem em uma instituição.

- ... é colocar ordem na unidade em que vai trabalhar tanto em relaçāo aos materiais e equipamentos... para que possa atender o cliente da melhor forma possivel.

- ... como devemos organizar, planejar e avaliar uma ala hospitalar.

- ... a maneira com a qual a enfermeira organiza e dirige a sua unidade...

- ... onde iremos aprender como organizar, coordenar e supervisionar o serviço de enfermagem.

- ... é a maneira de organizar e dirigir em enfermagem... para que se possa usufruir e conseguir um melhor serviço...

- ... promover e organizar uma unidade ou serviço... promovendo assim. uma melhor distribuiçāo do serviço.

- ... é a maneira pela qual se organiza o trabalho...

- ... é a maneira que a enfermeira faz uso em seu dia a dia para organizar o serviço, a máo-de-obra disponivel e os recursos existentes... utilizando assim, uma assistência adequada ao paciente.

- ... é fazer com que aquele espaço físico onde a enfermeira atua seja organizado...

- ... estabelecer atividades para os funcionários de acordo com sua funçäo... controlar o material... ter uma visão, um todo do funcionamento de uma unidade.

Essas falas vêm de encontro à abordagem científica e tradicional da administração no enfoque de Taylor e Fayol. 
Segundo CHIAVENATO ${ }^{2}$, administrar para Taylor significa planejar e racionalizar as tarefas que devem ser executadas pelos subordinados. A preocupação básica da administração é a metodização do trabalho com o objetivo de melhorar a eficiência do processo produtivo. É portanto, prescrever a maneira pela qual as pessoas devem executar o seu trabalho cotidiano.

CHLAVENATO ${ }^{2}$ mostra que Fayol amplia o enfoque de Taylor, definindo que administrar é sobretudo planejar e organizar a estrutura de órgāos e de cargos que compōem uma instituiçāo, dirigindo e controlando suas atividades.

TREVIZAN ${ }^{11}$ afirma que a introduçāo dos princípios da administração científica, elaborados por esses teóricos, na enfermagem, datam da época de Florence Nithingale, que formava enfermeiras com a preocupação de organizar e racionalizar o trabalho.

Para esta autora, o corpo de enfermagem incorporou o enfoque administrativo de Taylor e Fayol, principalmente, no que se refere ao desempenho dos auxiliares e atendentes de enfermagem.

Acredita-se que entre os objetivos da enfermagem a a proposta destes teóricos, evidencia-se o estabelecimento de critérios prescritivos e normativos para o desenvolvimento das atividades de enfermagem.

A divisāo do trabalho aliada a padronizaçāo das tarefas, a elaboração ou adoção de manuais de procedimentos tem sido uma das maiores preocupaçōes das enfermeiras que assumem a responsabilidade dos serviços de enfermagem ${ }^{6}$ fazer".6

Assim, a preocupação constante das enfermeiras tem sido com "o como

As falas das alunas, também, revelam o significado da administração como uma ciência e uma arte.

- ... é a ciência que vai nos auxiliar no planejamento e organizaçāo do ambiente hospitalar... visando o bom funcionamento do ambiente hospitalar, segundo as necessidades do paciente.

- ... é a aprendizagem desta ciência e a sua utilizaçāo e aplicação na enfermagem.

- ... é a arte de organizar um serviço de maneira clara e objetiva...

KOONTZ et al. ${ }^{5}$ relatam que somente agora é que está se desenvolvendo uma ciência de administração. Adotam a posição da administração como uma arte, uma vez que para se chegar à melhor prática, o conhecimento organizado em administração, deve ser aplicado às realidades de qualquer situação, nāo havendo uma "maneira ideal e universal de fazer coisas em todas as circunstâncias".

Para esses autores administraçāo representa a aplicaçāo de conhecimentos à realidade com vista à obtenção dos resultados desejáveis.

KAST; ROSENZWEIG ${ }^{4}$ afirmam que os conceitos clássicos continuam a fazer parte do pensamento gerencial contemporáneo. $E$ para esse autor os 
conceitos e a prática da administração são influenciados pelas ideologias da sociedade, não havendo ainda um corpo de conhecimentos internamente unificado.

2. Compreensão das alunas quanto a função administrativa como papel da enfermeira.

Nesse tema as alunas revelam como compreendem a funçāo administrativa da enfermeira, evidenciando o papel conciliatório entre a assistência e os objetivos da organização.

- ... é um dos papéis que a enfermeira deve exercer em uma unidade... de forma organizada e com liderança.

- ... é saber conciliar a assistência de enfermagem com a organizaçāo e gerenciamento político-econômico e recursos humanos e materiais dentro de uma instituição.

- ... é o papel que a enfermeira exerce em um hospital, em relação à equipe de enfermagem e de sua organizaçâo.

- ... é a maneira com a qual a enfermeira organiza e dirige a sua unidade, cuidando da parte burocrática, mas sem esquecer o aspecto assistencial ao paciente.

- ... a enfermagem numa instituiçāo necessita de uma administração, esta acredito deve conciliar a prática de enfermagem com o aspecto burocrático pertencente à instituiçào.

Pelas falas verifica-se, que as alunas ao iniciarem a disciplina Administração aplicada à Enfermagem, trazem a visão de que administração aplicada à enfermagem é o exercício da burocracia, associando-a com ineficiência administrativa.

KAST; ROSENZWEIG 4 afirmam que Weber, fundador da teoria da burocracia, nāo usava a palavra burocracia no sentido popular de excesso de formalismo e de ineficiência. O conceito de burocracia nāo tem conotação de bom ou de mau, mas sim se refere a certas características do esquema organizacional formal voltado, exclusivamente, para a racionalidade e eficiência.

O modelo teórico da burocracia, segundo CHLAVENATO ${ }^{2}$, enfoca a burocracia como a forma mais eficiente que existe para gerir as organizaçóes complexas. Seu modelo inclui dimensōes como uma hierarquia de autoridade bem definida, a divisão de trabalho com base na especialização funcional, um sistema de regras, impessoalidade das relaçōes, um sistema de trabalho e a colocação de pessoas, baseada na capacidade técnica. 
Estudiosos da burocracia que empreenderam uma revisão do esquema weberiano, reinterpretam as características da burocracia à luz do conceito de disfunçāo, uma vez que as organizaçōes são influenciadas por fatores ligados ao comportamento que não foram considerados por Weber.

MERTON ${ }^{9}$ mostrou que uma das conseqüèncias da rigidez burocrática é a despersonalização do relacionamento devido ao rígido apego às normas e regulamentos.

Nas instituiçōes de saúde encontramos, freqüentemente, formas organizacionais burocráticas. E o serviço de enfermagem seguem o modelo burocrático da instituição, nas suas estruturas e dinâmicas.

$O$ pessoal de enfermagem passa a ter caracteristicas profissionais de técnicos especializados, com comportamentos e posiçōes estrategicamente defendidas pelo grupo que detem o poder na organização. A valorização das normas e regras parece ser, o enfoque da burocracia, que mais tem influenciado a enfermagem, contribuindo para torná-la uma prática administrativa estanque, baseada em regras e normas obsoletas com poucas perspectivas de mudanças.

Dessa forma, a administração na enfermagem sofre o mal de uma disfunção da teoria burocrática.

\section{Compreensão das alunas quanto ao foco de atenção da enfermagem.}

Depreende-se pelas respostas das alunas, que compreendem a enfermagem tendo como foco de atençāo a assistência ao paciente internado, priorizando, assim, o aspecto curativo. As falas revelam a preocupação em assistir ao paciente internado, hospitalizado, individualizado, não levando em consideração a assistência à família e nem à comunidade.

- ... tendo como objetivo o paciente...

- ... segundo às necessidades do paciente...

- ... uma assistência adequada ao paciente...

- ... a enfermeira atua.. de tal forma que a assistência a ser prestada ao paciente seja adequada às suas necessidades.

Considera-se que essas falas são reflexo das condiçōes econômicas, sócio-culturais e políticas do País, que nāo valorizam a participação dos indivíduos e da comunidade, no planejamento, organizaçāo, funcionamento e controle da atenção primária à saúde.

Segundo LIMA ${ }^{7}$, o quadro sanitário do País é inoperante e está estruturado de forma a contemplar a falta de coordenação nas açōes de saúde, a multiplicidade de sistemas de prestação de serviço e que a atual reforma 
sanitária por meio da implantação do SUS (Sistema Único de Saúde), ainda, não conseguiu superar essas dificuldades.

As a firmaçōes de LIMA ${ }^{7}$ revelam que a forma de organizaçāo do setor saúde tem influenciado a prática e o ensino de enfermagem.

Acredita-se que essa situaçāo é um fator determinante do currículo vigente na EEUSP, o qual tem contemplado os aspectos curativos da assistência de enfermagem, pois a abordagem na área preventiva, de maneira formal, dá-se, apenas no $7^{\mathbb{R}}$ semestre do curso.

Acredita-se também, que o conhecimento da opinião das alunas sobre o significado da administração aplicada à enfermagem, ao iniciarem a disciplina Administração aplicada à Enfermagem, possibilitará às docentes, da referida disciplina, à reflexão do ensino, a fim de torná-lo mais próximo da realidade concreta das alunas, capacitando-as para aplicarem os conhecimentos de administração na prática profissional.

\section{CONCLUSŌES}

O presente estudo permitiu chegar às seguintes conclusōes:

1 - as alunas percebem a administraçāo dentro da abordagem clássica e tradicional desenvolvida por Taylor e Fayol;

2 - as alunas compreendem como o objetivo da administração aplicada à enfermagem a melhora da qualidade do serviço, do trabalho, nâo enfocando o lado do trabalhador;

3 - as alunas entendem que a função administrativa da enfermeira consiste em conciliar a assistência de enfermagem com a burocracia do serviço;

4 - as alunas estão voltadas para a assistência de enfermagem no enfoque curativo.

KURCGANT, P.et al The iignificance of administration applied to the nursing practice felt by nursing students. Rev. Esc. Enf. USP, v. 28, n.1, p. 15.26, Apr., 1994.

The objective of this study was to know the opinions that the students have, when, when they begin the course of Administration applied of Nursing. The results indicated that 2 d that the students considered administration a manner how the nurses are organizing their tg thei works and that nursing activity administration is to conciliate the assistence with the vith th bureaucratic service.

\section{REFERÊNCIAS BIBLIOGRÁFICAS}

01. ALMEIDA, M.C.P. de. Proceaso e divisão do trabalho na enfermagem. In: CONGRESSO BRASILEIRO DE ENFERMAGEM, 39, Salvador, 1987. Anais. Salvador, Associaçáo Brasileira de Enfermagem-Seçáo Bahia, 1988. p.19-26. 
02. CHIAVEnATO, I. Administraçào: teoria, processo e prática. Sāo Paulo, McGraw. Hill, 1985.

03. CONSELHO FEDERAL DE ENFERMAGEM. O exercicio da enfermagem nas instituiçóes de saúde no Brasil 1982.1983: força do trabalho em enfermagem. Rio de Janeiro, Associação Brasileira de Enfermagem, 1985. v.1.

04. KAST, F.E.; ROSENZWEIG, J.E. Organizaçāo e administraçāo: um enfoque sistèmico. 2.ed. São Paulo, Pioneira, 1980.

05. KOONTZ, H. et al Administraçào: fundamentos da teoria e da ciência. Sāo Paulo, Pioneira, 1986.

06. KURCGANT, P.(coord.) Administraçio em enfermagem. Sāo Paulo, EPU, 1991. Cap.1,p.3.13: As teorias de administraçäo em enfermagem.

07. LIMA,R. de C.D. Contradiçōea do enaino e prática de enfermagem: percepçāo dos enfermeiros egressos do curoo de graduaçāo em enfermagem da UFES. Vitória, 1988. 180p. Dissertação (Meatrado). Universidade Federal do Espírito Santo.

08. LüDKE, M.; ANDRE, M.E.D.A. Pesquisa em educaçào: abordagens qualitativas. Sảo Paulo,EPU, 1986.

09. MERTON, R.K. Estrutura burocrática e personalidade. In: CAMPOS, E. Sociologia da burocracia. Rio de Janeiro, Zahar, 1966. p.96-110.

10. NAKAMAE, D.D. Novos caminhos da enfermagem. São Paulo, Cortez,1987.

11. TREVIZAN, M.A. Enfermagem hoepitalar: administraçào e burocracia. Brasília, Editora Univeroidade de Brasúlia, 1988. 


\section{ANEXO \\ O QUE É ADMINISTRAÇĀO APLICADA À ENFERMAGEM?}

1. Nào sei.

2. É um dos papéis que a enfermeira deve exercer em uma unidade pois é responsável por uma equipe e por pacientes e portanto deve ser feito de uma forma organizada e com liderança.

3. É organizar, coordenar, orientar e fiscalizar um setor do hospital. Isto engloba o bom funcionamento da unidade.

4. Organização das tarefas ligadas a área de enfermagem em uma instituição.

5. Administraçáo a plicada à enfermagem é colocar ordem na unidade em que vai trabalhar tanto em relaçāo aos materiais e equipamentos necessários a determinados procedimentos e em relaçáo aos funcionários para que possa atender o cliente da melhor forma possivel.

6. É todo processo definido anteriormente aplicado no processo de enfermagem, ou seja, para a execução da enfermagem, é necessário uma organização, um gerenciamento sistematizado.

7. É saber conciliar a assistência de enfermagem com a organizaçāo e gerenciamento político-econômico e recursos humanos e materiais dentro de uma instituiçāo.

8. É o curso responsável para ministrar como devemos organizar, planejar e avaliar uma ala hospitalar.

9. É uma área que aborda, principalmente, as questóes citadas na pergunta anterior, porém, aplicáveis à enfermagem, ou seja, o trabalho de equipe (técnicos. auxiliares, atendentes), a área burocrática hospitalar, entre outras coisas.

10. Líder organizando as atividades de enfermagem de forma satisfatória tanto para o funcionário, e conseqüentemente, para uma melhor assisténcia.

11. É saber ordenar, coordenar, supervisionar, fazer e ensinar uma assistência de enfermagem. Desde a assisténcia direta que é dada ao paciente até o ambiente, funcionários, material que compóe o serviço de enfermagem.

12. É o papel que a enfermeira exerce em um hospital, em relaçāo à equipe de enfermagem e de sua organizaçào. 
13. Acredito que seja a maneira com a qual a enfermeira organiza e dirige a sua unidade, cuidando da parte burocrática, mas sem esquecer o aspecto assistencial ao paciente. $\dot{E}$ como se fosse o modo e as técnicas usadas para prestar uma melhor assistência, tendo como objetivo o paciente, voltando sua atençảo à equipe como un todo.

14. Onde iremos aprender a organizar, coordenar e supervisionar o serviço de enfermagem.

15. É administrar todos os cuidados aplicados ao paciente, com isso orientar funcionários e/ou pacientes e familiares, organizar os cuidados a serem prestados para que haja uma melhor e mais rápida melhora do paciente.

16. É aprendizagem desta ciência é a sua utilização e aplicação na enfermagem.

17. Estabelecer atividades para os funcionários de acordo com sua função, fazer controle de estoques de material, ter a visão de um todo do funcionamento de uma unidade.

18. É a maneira de organizar e dirigir em enfermagem para que se possa usufruir e conseguir um melhor serviço.

19.

20. A enfermagem numa instituiçảo necessita de uma administraçāo, esta, acredito deve conciliar a prática de enfermagem com o aspecto burocrático pertencente à instituiçāo.

21. Administrar em enfermagem, seria eu acho, promover e organizar uma unidade ou serviço, promovendo assim uma melhor distribuiçāo do serviço tornando-o de melhor qualidade (burocrático).

22. É a ciência que vai nos auxiliar no planejamento e organizaçáo do ambiente hospitalar, visando o bom funcionamento deste, segundo as necessidades do paciente.

23. E a maneira pela qual se organiza o trabalho como um todo, dentro da área de enfermagem.

24. É a elaboraçāo de um plano de assistência dirigido ao paciente como um todo. Deve fazer parte deste plano tudo aquilo que direta ou indiretamente contribui para o seu restabelecimento (compra de material, escala de funcionários, limpeza da unidade, orientaçáo, assistência direta ao paciente, etc.)

25. É a arte de organizar um serviço de maneira clara, objetiva, utilizando os recursos humanos e pessoais existentes a fim de propor um bom relacionamento en. tre os seus funcionários e a produçào com qualidade e quantidade. 
26. É a administraçāo da assistència de enfermagem.

27. É um ramo de estudo que trata sobre como o enfermeiro deve administrar uma unidade do hospital. É um curso que proporciona noçóes de administraçáo da área de enfermagem.

28. É a maneira que a enfermeira faz uso em seu dia a dia para organizar o serviço, a māo-de-obra disponível e os recursos existentes, utilizando assim uma assis. tência adequada ao paciente.

29. É a forma de organizar, dirigir e sistematizar a assistência de enfermagem prestada ao individuo, familia e comunidade e que, direta ou indiretamente atenda as necessidades básicas.

30. É fazer com que aquele espaço físico onde a enfermeira atua seja organizado de tal forma que a assistência prestada ao paciente seja adequada às suas necessidades. É tentar organizar um trabalho em equipe. 